\title{
Buji Ateşlemeli Bir Motorda Yüksek Performans ve Düşük Emisyon Elde Etmek Amaciyla Kullanılacak Optimum Metanol Oranının Cevap Yüzey Metodu ile Belirlenmesi
}

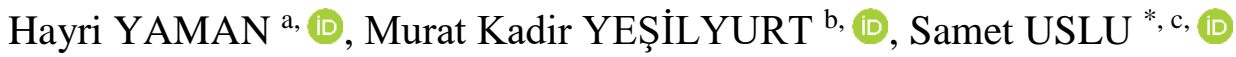 \\ ${ }^{a}$ Kırıkkale Üniversitesi Kırıkkale Meslek Yüksekokulu Otomotiv Teknolojisi Programı, 71451, KIRIKKALE, TÜRKIYE \\ ${ }^{b}$ Yozgat Bozok Üniversitesi Mühendislik-Mimarlık Fakültesi Makine Mühendisliği Bölümü, 66200, YOZGAT, TÜRKIYY \\ c, " Karabük Üniversitesi Mühendislik Fakültesi Makine Mühendisliği Bölümü, 78050, KARABÜK, TÜRKIYE
}

\section{MAKALE}

BÍLGISİ

Alınma: 12.05.2021

Kabul: 25.12.2021

\section{Anahtar Kelimeler:}

Optimizasyon

Cevap Yüzey Metodu

Metanol

Buji Ateşlemeli Motor
$\ddot{\mathrm{OZZ}}$

Bu çalışmada, buji ateşlemeli bir motorda alternatif yakıt olarak kullanılan metanolün performans ve emisyonlar açısından optimum seviyesinin cevap yüzey metodu ile belirlenmesi amaçlanmıştır. $\mathrm{Bu}$ amaçla, benzine hacimsel olarak üç farklı oranda metanol (\%0, \%10 ve \%20) ilave edilerek oluşturulan yakıt karışımları ile tek silindirli, dört zamanlı, su soğutmalı, buji ateşlemeli bir motorda farklı motor yüklerinde $(6,8,10,12$ ve $14 \mathrm{~kg})$ deneyler gerçekleştirilmiştir. Elde edilen deney sonuçları ile iki faktörlü merkezi kompozit tam tasarım kullanılarak varyans analizi destekli bir cevap yüzey modeli oluşturulmuş ve en iyi fren efektif verimi, fren özgül yakıt tüketimi, karbon monoksit, hidrokarbon, karbondioksit ve azot monoksit emisyonu seviyelerine karşılık gelen optimum metanol oranı ve motor yükü değerleri tespit edilmiştir. Elde edilen optimizasyon sonuçlarına göre optimum metanol oranı $\% 7$ çıkarken, optimum motor yükü $12 \mathrm{~kg}$ olarak bulunmuştur. Optimum metanol oranı ve motor yüküne karşlık gelen fren efektif verimi, fren özgül yakıt tüketimi, karbon monoksit, hidrokarbon, karbondioksit ve azot monoksit sirasıyla $\% 32,037,0,251 \mathrm{~kg} / \mathrm{kWh}, \% 0,384,110,05 \mathrm{ppm}, \% 14,35$ ve 1090,358 ppm olarak elde edilmiştir. Cevap yüzey metodu sonuçlarının doğruluğunun belirlenmesi için elde edilen optimum metanol ve motor yükü ile deneyler gerçekleştirilmiş ve cevap yüzey metodu sonuçları ile kıyaslanmıştır. Optimizasyon sonuçlarının deney sonuçları ile \%6'dan daha düşük bir hata oranı ile uyumlu olduğu ve optimum metanol oranının tespiti için cevap yüzey metodunun etkili olarak kullanılabilecek bir araç olduğu sonucuna varılmıştır.

\section{Determination of Optimum Methanol Ratio to be Used with the Aim of Obtaining High Performance and Low Emissions in a Spark Ignition Engine by Response Surface Methodology}

\section{ARTICLE \\ INFO \\ Received: 12.05 .2021 \\ Accepted: 25.12 .2021}

\section{Keywords:}

Optimization

Response Surface

Methodology

Metanol

\begin{abstract}
In the present study, it is aimed to identify the optimum level of methanol used as an alternative fuel in a spark ignition engine in terms of performance and emissions by the response surface methodology. For this purpose, three different fractions of methanol $(0 \%, 10 \%$ and $20 \%)$ by volume were added to gasoline and the prepared test fuels were experimented in a single-cylinder, four-stroke, water-cooled, spark ignition engine at various engine loads $(6,8,10,12$, and $14 \mathrm{~kg})$. The model was developed supported with analysis of variance by using the two-factorial central composite full design and the optimum methanol concentration and engine load values were determined corresponding to the best brake thermal efficiency, brake specific fuel consumption,
\end{abstract}

*Sorumlu yazar: sametuslu@karabuk.edu.tr

To cite this article: H. Yaman, M.K. Yeşilyurt ve S. Uslu, "Determination of Optimum Methanol Ratio to be Used with the Aim of Obtaining High Performance and Low Emissions in a Spark Ignition Engine by Response Surface Methodology", Gazi Journal of Engineering Sciences, vol.7, no.3, pp. 346-358, 2021. doi:10.30855/gmbd.2021.03.16 


\begin{abstract}
carbon monoxide, hydrocarbon, carbon dioxide and nitrogen monoxide emission levels. According to the optimization results, while the optimum methanol ratio was found to be $7 \%$, the optimum engine load was found to be $12 \mathrm{~kg}$. Corresponding to the optimum methanol ratio and engine load; brake thermal efficiency, brake specific fuel consumption, carbon monoxide, hydrocarbon, carbon dioxide and nitrogen monoxide were obtained as $32.037 \%, 0.251 \mathrm{~kg} / \mathrm{kWh}$, $0.384 \%, 110.05 \mathrm{ppm}, 14.35 \%$ and $1090.358 \mathrm{ppm}$, respectively. In order to determine the sensitivity of the response surface methodology results, the experiments were performed with optimum methanol ratio and engine load and compared with response surface methodology results. It was concluded that the optimization results were compatible with the experimental results with an error rate of less than $6 \%$ and that response surface methodology is an effective tool to determine the optimum methanol ratio.
\end{abstract}

https://dx.doi.org/10.30855/gmbd.2021.03.16

\section{GIRIŞ (INTRODUCTION)}

Günümüz dünyasının daha yaşanabilir bir hale gelmesi için yapılan çalışmalar tüm insanlık tarafindan devam etmektedir. Özellikle son yüzyılda gelişen teknoloji, sanayileşme ve kentselleşme ile artan hava kirliliği, insanlığı ve diğer canlıları direkt etkileyecek boyutlara ulaşmıştır [1, 2]. Bu yüzden hava kirliliğini azaltmaya yönelik çalıșmalar hız kazanmıştır. Hava kirliğine sebep olan unsurların başında motorlu taşıtlardan kaynaklanan hava kirliliği gelmektedir. 2009 yılında dünya genelinde arazi araçları ve ağır iş makineleri hariç, yaklaşık 940 milyon motorlu araç kullanılmakta iken, 2011 y1lı itibariyle bu sayı 1 milyarı geçmiştir [3]. 2018 yılına gelindiğinde ise dünya genelinde 1.3 milyar motorlu taşıt bulunduğu, günümüzde ise bu rakamın yaklaşık 2 milyar olduğu belirtilmektedir. Motorlu araç sayısındaki önlenemez bu artış beraberinde hava kirliliğini de getirmektedir. Hem bu kirliliğin önüne geçebilmek, en azından azaltabilme, hem de azalan fosil yakıt rezervlerine alternatif olabilmesi amaciyla fosil yakıtların yerini alabilecek temiz yakıt arayışı günden güne hızlanarak devam etmektedir [4].

Buji ateşlemeli motorlarda performans ve emisyon açısından önemli bir kriter kullanılan yakıtın oktan sayısıdır. Yüksek oktan sayısı beraberinde yüksek verim ve düşük emisyon getirmektedir. Buna istinaden, benzine kıyasla daha yüksek oktan sayısına sahip olan alkoller buji ateşlemeli motorlar için ideal bir alternatif yakıttır $[5,6]$. Alkollerin yüksek oktan değerleri ve daha yüksek buharlaşma 1sısı değerleri, onları yüksek sıkıştırma oranlı motorlar için uygun yakıtlar haline getirmektedir [7, 8]. Alternatif yakıt olarak kullanılabilecek birçok yakıt olmakla birlikte metanol en çok tercih edilen alkol yakıtların başında gelenlerdendir. Metanol nişasta ekinlerinin fermente edilmesi ve damıtılmasıyla, doğalgazdan, kömürün gazlaştırılmasından, odundan, samandan, bitki saplarından, çöpten ve hatta yanıcı çöplerden de üretilebilmektedir [9-11]. Buna ilaveten, talaş, pirinç kepeği ve pirinç kabuğu gibi biyoyakit kaynaklarından da metanol üretilebilmektedir [12]. Metanol yüksek oktan sayısına, oksijen oranına, düşük karbon/hidrojen oranına sahiptir ve yenilenebilir bir yakıt olarak kabul edilmektedir [13, 14]. Metanol ayrıca motora giren havayı soğutan ve hacimsel verimliliği ve güç çıkışını artıran yüksek bir 1sı buharlaşma oranına sahiptir [15]. Ancak, soğuk çalıştırma ve daha düşük gizli 1sıtma değeri gibi olumsuz etkileri de vardır.

Metanolün buji ateşlemeli motorlarda kullanımı ile alakalı geçmişten günümüze çok sayıda çalışma mevcuttur. Prasad vd. [16] tek silindirli dört zamanlı değişken sıkıştırma oranlı buji ateşlemeli bir motor üzerinde $1200 \mathrm{~d} / \mathrm{d}$ ile $1800 \mathrm{~d} / \mathrm{d}$ arasında değişen farklı hızlarda, üç farklı sıkıştırma oranında $(8: 1,9: 1$ ve 10:1) metanol kullanıminın performans ve emisyonlara etkisini incelemişlerdir. Benzine \%50 metanol ilave ederek oluşturdukları test yakıtının, 10:1 sıkıştırma oranı değerinde performans ve emisyon açısından en iyi değerleri verdiğini ifade etmişlerdir. Diğer bir çalışmada Balki vd. [12] 8.5:1 sıkıştırma oranına sahip, hava soğutmalı, tek silindirli bir buji ateşlemeli motorda saf etanol, metanol ve benzin kullanarak sıkıştırma oranının ve yakıt türlerinin motor performans1, yanma ve emisyon özellikleri üzerindeki etkilerini deneysel olarak incelemişlerdir. Tüm sıkıştırma oranlarında, etanol ve metanol yakıt karışımlarının fren efektif verimi (FEV) ve fren özgül yakıt tüketimi (FÖYT) değerlerinin benzine göre daha yüksek olduğunu belirtmişlerdir. Buna ilaveten, genel olarak, saf etanol ve metanol kullanımı ile tüm sıkıştırma oranlarında benzin emisyonlarına kıyasla daha düşük bir egzoz emisyonu bulunduğunu ifade etmişlerdir. Çay vd. [17] yapay sinir ağları kullanarak metanol yakıtının performans ve egzoz emisyonları üzerindeki etkilerini araştırmışlar ve benzine kıyasla metanol kullanımıyla emisyonlarda iyileşme sağlandığı sonucuna ulaşmışlardır.

Alternatif yakıt arayışındaki araştırmacılar yakıt türünün uygunluğunu belirlemek, performans ve 
emisyonlara etkilerini incelemek ve optimum seviyelerini tespit etmek amaciyla para, zaman ve enerji harcayarak çok sayıda deneysel çalışma yapmak zorunda kalmaktaydılar. Son y1llarda ise gelişen bilgisayar teknolojileri sayesinde az sayıda deney ile alternatif yakıt uygunluğunu belirleyebilecekleri uygulamalar geliştirilmiştir. $\mathrm{Bu}$ uygulamalardan biri olan cevap yüzey metodu (RSM), optimum cevaplar elde etmek ve her bir giriş parametresinin çıkış cevapları üzerindeki etkisini belirlemek amaciyla ideal girdi kombinasyonunu oluşturabilen bir bilgisayar uygulamasıdır [18].

Literatürde farklı alkol tiplerinin buji ateşlemeli motorlarda kullanımı ile alakalı RSM ile yapılan optimizasyon çalışmaları olmakla birlikte [19-22], metanol ile ilgili RSM optimizasyon çalışması son derece kısıtlıdır. Bu çalışmada, optimum metanol ve motor yükünün belirlenerek, buji ateşlemeli motordan maksimum performans ve minimum emisyon elde edilmesi amaciyla RSM ile optimizasyon gerçekleştirilmiştir.

\section{MATERYAL VE METOT (MATERIALS AND METHODS)}

$\mathrm{Bu}$ çalışmada tek silindirli buji ateşlemeli bir motorda alternatif yakıt olarak kullanılacak olan metanolün performans ve emisyon cevapları açısından optimum oranının tespit edilmesi amaçlanmıştır. $\mathrm{Bu}$ amaçla, farklı motor yükü değerlerinde $(6,8,10,12$ ve $14 \mathrm{~kg})$ ve hacimsel olarak üç farklı metanol oranında $(\% 0, \% 10$ ve $\% 20)$ deneyler gerçekleştirilmiştir. Elde edilen deneysel veriler kullanılarak RSM modeli oluşturulup optimizasyon çalışmaları yapılmıştır. Deneysel çalışmalarda kullanılan yakıtların bazı önemli fiziksel ve kimyasal özellikleri Tablo 1'de verilmiştir.

Tablo 1. Yakıt özellikleri (Fuel properties) [23-25]

\begin{tabular}{lcc}
\hline Özellikler & Benzin & Metanol \\
\hline Kimyasal formül & $\mathrm{C}_{7} \mathrm{H}_{16}-\mathrm{C}_{8} \mathrm{H}_{18}$ & $\mathrm{CH}_{3} \mathrm{OH}$ \\
Molekül ağırlığı $(\mathrm{g} / \mathrm{mol})$ & $100-114$ & 32 \\
Yoğunluk $\left(\mathrm{g} / \mathrm{cm}^{3}\right)$ & $0,720-0,775$ & 0,790 \\
Alt ısıl değer $(\mathrm{MJ} / \mathrm{kg})$ & 44,0 & 20,05 \\
Oktan sayısı & 95 & 111 \\
Oksijen içeriği (\% ağırlık) & 0 & 50 \\
Kaynama noktası $\left({ }^{\circ} \mathrm{C}\right)$ & $38-210$ & 64 \\
Kinematik viskozite & $0,37-0,44$ & 0,59 \\
$\left(40{ }^{\circ} \mathrm{C}\right.$ 'de) $\left(\mathrm{mm}^{2} / \mathrm{s}\right)$ & & \\
\hline
\end{tabular}

Deneyler tek silindirli, dört zamanlı, sıkıştırma oranı ayarlanabilir Kirloskar marka TV1 model buji ateşlemeli bir motorda gerçekleştirilmiştir. Motorun teknik özellikleri Tablo 2'de gösterilmiştir. Motorun yüklenmesi için Galen-Tech marka, hava soğutmalı AC dinamometre ve Siemens Sinamics G120 dinamometre yükleme ünitesi kullanılmıştır. Motorun kontrolü PE3-SP000 serisi elektronik kontrol ünitesi ile gerçekleştirilmiştir. Deney düzeneğinin şematik olarak gösterimi Şekil 1'de verilmiştir.

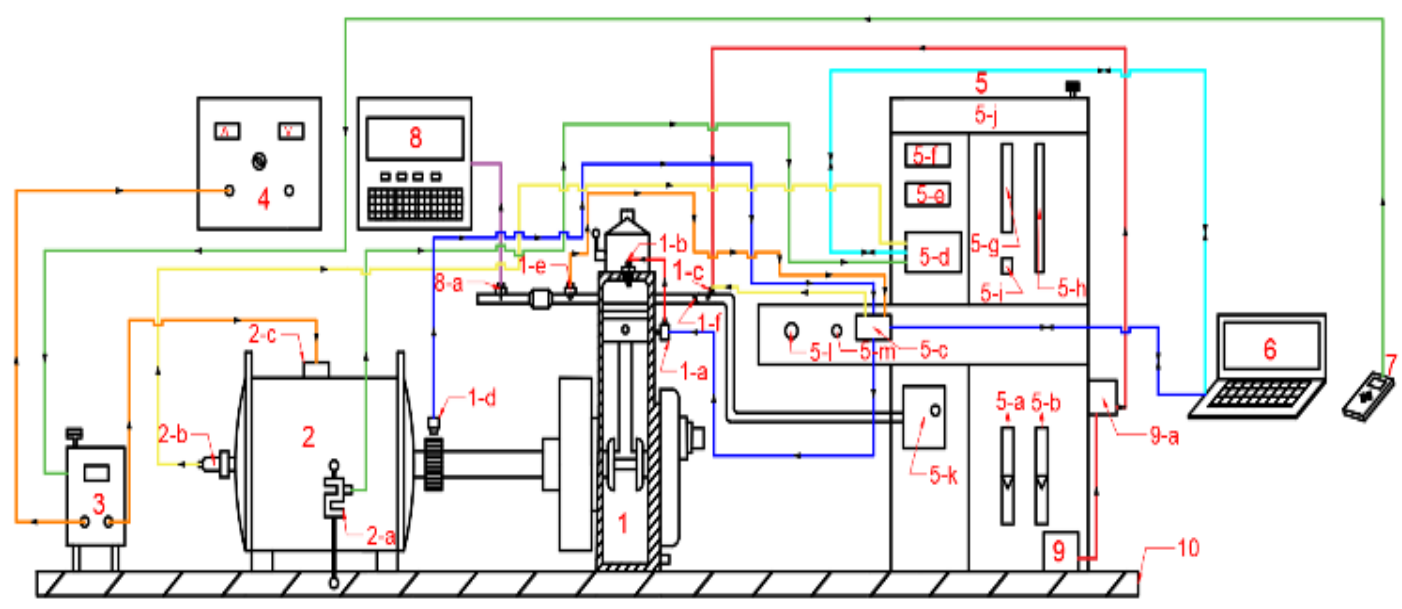

Şekil 1. Deney düzeneğinin şematik gösterimi (Schematic representation of the experimental setup):

1-motor, 1-a ateşleme bobini, 1-b buji, 1-c benzin enjektörü, 1-d hall efekt sensörü, 1-e $\mathrm{O}_{2}$ sensörü, 1-f gaz kelebeği, 2- dinamometre, 2-a yük hücresi, 2-b enkoder, 2-c dinamometre ve hız kontrol bağlantısı, 3- dinamometre hız kontrol ünitesi $11 \mathrm{~kW}, 4$ - AC dinamometre $380 \mathrm{~V}$ kart, 5 adet ölçüm elemanı sehpası, 5-a motor soğutma rotametresi, 5- b egzoz kalorimetre rotametresi, 5-c benzinli motor elektronik kontrol ünitesi, 5-d veri toplama cihazı, 5-e yük göstergesi, 5-f devir göstergesi, 5-g manometre, 5-h yakıt ölçüm büreti, 5-i yakıt musluğu, 5 -j yakıt deposu, 5-k motor emiş havası ölçüm sistemi, 5-1 gaz kelebeği konum kontrol sistemi, 5-m sistem anahtarı, 6bilgisayar ara yüzü, 7-yük ve hız kontrol ara yüz cihazı, 8-gaz analiz cihazı, 9-benzin enjeksiyon pompası, 9-a benzin filtresi 
Tablo 1. Deney motorunun teknik özellikleri (Technical specifications of the test engine)

\begin{tabular}{ll}
\hline Marka & Kirloskar VCR motor \\
Model & TV 1 \\
Tipi & Tek silindirli ve dört zamanlı \\
Anma gücü & $7,5 \mathrm{~kW}$ \\
Maksimum motor hızı & $1850 \mathrm{~d} / \mathrm{d}$ \\
Çap x Strok & $87,5 \mathrm{~mm}$ x $110 \mathrm{~mm}$ \\
Silindir hacmi & $661,5 \mathrm{cc}$ \\
Sikıştırma oranı & $6: 1-10: 1$ \\
Soğutma tipi & Su soğutmalı \\
Rölanti devri & $750 \mathrm{~d} / \mathrm{d}$ \\
Yük kapasitesi & $0-50 \mathrm{~kg}$ \\
\hline
\end{tabular}

FEV ve FÖYT değerlerinin hesaplanması için aşağıda gösterilen denklem 1 ve denklem 2 sırasıyla kullanılmıştır.

$$
\mathrm{FEV}=\frac{\mathrm{Pe} * 3600}{\mathrm{~B} * \mathrm{Hu}}
$$

$$
\mathrm{FÖYT}=\frac{\mathrm{B} * 1000}{\mathrm{Pe}}
$$

Burada Pe motor gücü, B saatlik yakıt tüketimi ve $\mathrm{Hu}$ yakıtın alt 1sıl değerini ifade etmektedir.

Bosch marka BEA 350 model egzoz gazı analizörü ile egzoz gazı emisyonları ölçülmüştür. Egzoz gazı analizörünün teknik özellikleri Tablo 3'te gösterilmiştir.

Tablo 2. Egzoz gazı analizörünün teknik özellikleri

\begin{tabular}{lll}
\multicolumn{3}{c}{ (Technical properties of exhaust gas analyzer) } \\
\hline Özellik & Birim & Ölçüm aralığı \\
\hline Karbon monoksit $(\mathrm{CO})$ & $\%$ hac. & $0-10$ \\
Karbondioksit $\left(\mathrm{CO}_{2}\right)$ & $\%$ hac. & $0-18$ \\
Hidrokarbon $(\mathrm{HC})$ & ppm & $0-9999$ \\
Azot monoksit $(\mathrm{NO})$ & ppm & $0-5000$ \\
$\lambda$ & - & $0,500-9,999$ \\
\hline
\end{tabular}

Yapılan hesaplamalar ve ölçümler sonunda elde edilen deneysel sonuçlar Tablo 4'te verilmiştir.

Tablo 4. Deney sonuçları (Experimental results)

\begin{tabular}{lccccccc}
\hline $\begin{array}{l}\text { Metanol } \\
\text { Oranı (\%) }\end{array}$ & $\begin{array}{c}\text { Yük } \\
(\mathbf{k g})\end{array}$ & $\begin{array}{c}\mathbf{C O} \\
(\boldsymbol{\%})\end{array}$ & $\begin{array}{c}\mathbf{H C} \\
(\mathbf{p p m})\end{array}$ & $\begin{array}{c}\mathbf{C O}_{\mathbf{2}} \\
(\boldsymbol{\%})\end{array}$ & $\begin{array}{c}\mathbf{N O}_{\mathbf{x}} \\
(\mathbf{p p m})\end{array}$ & $\begin{array}{c}\text { FÖYT } \\
(\mathbf{k g} / \mathbf{k W h})\end{array}$ & $\begin{array}{c}\mathbf{F E V} \\
(\boldsymbol{\%})\end{array}$ \\
\hline 0 & 6 & 0,59 & 145 & 15,05 & 621 & 0,37 & 22,50 \\
10 & 6 & 0,58 & 135 & 14,05 & 474 & 0,38 & 21,00 \\
20 & 6 & 0,46 & 139 & 14,62 & 487 & 0,37 & 21,60 \\
0 & 8 & 0,59 & 142 & 14,96 & 862 & 0,31 & 27,10 \\
10 & 8 & 0,65 & 130 & 13,83 & 742 & 0,32 & 24,47 \\
20 & 8 & 0,66 & 138 & 14,18 & 765 & 0,33 & 24,10 \\
0 & 10 & 0,46 & 123 & 15,22 & 1058 & 0,26 & 30,44 \\
20 & 10 & 0,41 & 131 & 14,33 & 904 & 0,29 & 27,15 \\
0 & 12 & 0,41 & 106 & 15,22 & 1200 & 0,25 & 32,45 \\
10 & 12 & 0,35 & 104 & 13,95 & 1048 & 0,26 & 33,00 \\
20 & 12 & 0,33 & 115 & 14,49 & 1002 & 0,26 & 30,03 \\
0 & 14 & 0,35 & 107 & 15,20 & 1238 & 0,24 & 34,70 \\
10 & 14 & 0,34 & 109 & 14,27 & 1196 & 0,24 & 34,00 \\
\hline
\end{tabular}

\subsection{Cevap Yüzey Yöntemi (Response Surface Methodology)}

Bir yanıt ya da yanıtlar ile bağımsız faktörler arasındaki korelasyona dayalı bir deneysel tasarım ve istatistiksel modelleme oluşturabilen, çok değişkenli tahmin ve optimizasyon yapabilen RSM, birçok mühendislik alanında tercih edilmesinin yanında içten yanmalı motorların modellenmesi ve optimizasyonu için de tercih edilen bilgisayar tabanlı bir uygulamadır [26-30]. RSM, gerekli deneysel çalışma sayısını önemli ölçüde azaltır ve seçilen modele dayalı olarak, faktörler arasındaki etkileşimin etkisini de belirleyebilir [31]. Deneysel sonuçlar, doğru tahmin için 2. dereceden bir polinom modelinin tepki regresyonu kullanılarak araştırılır [32]. Böyle bir sistemin davranışı, aşağıda denklem 3 'te açıklandığı gibi ikinci dereceden bir denklem kullanılarak kontrol edilir.

$$
y=\beta_{0}+\sum_{i}^{k} \beta_{i} x_{i}+\sum_{i=1}^{k} \sum_{j \geq i}^{k} \beta_{i j} x_{i} x_{j}+\text { ? }
$$

Burada $\beta_{0}$ sabit, $\beta_{i}$ doğrusal katsayı ve $\beta_{i j}$ etkileşim katsayısıdır. $i$ ve $j$ sırasıyla doğrusal ve ikinci 
dereceden katsayılardır. $\mathcal{E}$ rastgele test hatası, k faktör sayısı, y tahmin edilen yanıt, $x_{i}$ ve $x_{j}$ ise bağımsız faktörlerdir [33].

Bu çalışmada, optimum metanol oranı ve motor yükü seviyelerini belirlemek ve bunlara karşılık gelen optimum FEV, FÖYT, $\mathrm{CO}, \mathrm{CO}_{2}, \mathrm{HC}$ ve $\mathrm{NO}$ cevaplarını belirlemek amacıyla RSM uygulanmıştır. Seçilen faktörler seviyeleriyle birlikte Tablo 5'te sunulmuştur.

Tablo 5. Faktörler ve seviyeleri (Factors and their levels)

\begin{tabular}{lccccc}
\hline Faktör & \multicolumn{5}{c}{ Seviyeler } \\
\hline Metanol oranı (\%) & 0 & 10 & 20 & - & - \\
Motor yükü (kg) & 6 & 8 & 10 & 12 & 14 \\
\hline
\end{tabular}

RSM'nin yanı sıra, faktörlerin ortalamaları arasında anlamlı bir fark olup olmadığını görmek amacıyla varyans analizi (ANOVA) uygulanmıştır. ANOVA tablosunda dikkate alınması gereken en önemli kriterler F-değeri ve p-değeri'dir. Daha büyük F-değeri daha etkili bir faktör manasına gelmektedir. $\mathrm{F}$ istatistiği, genel sonuçların anlamlı olup olmadığına karar verirken, $\mathrm{p}$-değeri ile birlikte kullanılmalıdır. pdeğeri, F istatistiği tarafından belirlenir ve sonuçların tesadüfen gerçekleşmiş olma olasılığını ifade eder. Bir faktörün cevap üzerinde etkisinin olabilmesi için pdeğerinin 0,05 'ten düşük olması gerekmektedir [34, 35]. Tablo 6 bir parametrenin cevap üzerinde anlamlı etkisinin olup olmadı̆̆ını ifade eden p-değerlerini göstermektedir. 0,05 'ten büyük p-değerleri, parametrenin önemsiz olduğu veya yanıt üzerinde hiçbir etkisinin olmadığı anlamına gelmektedir. Tabloya bakıldığında motor yükünün lineer açıdan $\mathrm{CO}_{2}$ emisyonu dışında tüm cevaplarda anlamlı etkiye sahip olduğu görülmektedir.

Diğer taraftan, metanol oranının ise $\mathrm{CO}$ ve $\mathrm{HC}$ emisyonları dışında diğer tüm cevaplar üzerinde etkisi olduğu anlaşılmaktadır. Elde edilen regresyon sonuçları tüm yanıtlar için \%90'dan büyük $\mathrm{R}^{2}$ değerlerinin elde edildiği ve buna istinaden, oluşturulan RSM modelinin, farklı motor yükünde buji ateşlemeli motor cevapları üzerindeki metanol oranının etkisini doğru bir şekilde verme yeteneğine sahip olduğunu göstermektedir.

Tablo 6. Her bir cevap için ortaya çıkan p-değerleri ve $\mathrm{R}^{2}$ değerleri ( $p$-values and $R^{2}$ values resultant for each answer)

\begin{tabular}{lcccccc}
\hline & \multicolumn{5}{c}{ p-değeri } & \multirow{2}{*}{$\mathrm{R}^{2}$} \\
\hline Faktörler & $\mathrm{A}$ & $\mathrm{B}$ & $\mathrm{AB}$ & $\mathrm{A}^{2}$ & $\mathrm{~B}^{2}$ & $\% 97,99$ \\
FEV & $\mathbf{0 , 0 0 2}$ & $\mathbf{0 , 0 0 0}$ & 0,329 & 0,819 & 0,052 & $\% 99,02$ \\
FÖYT & $\mathbf{0 , 0 0 9}$ & $\mathbf{0 , 0 0 0}$ & 0,410 & 0,910 & $\mathbf{0 , 0 0 0}$ & $\% 90,11$ \\
$\mathrm{CO}$ & 0,578 & $\mathbf{0 , 0 0 3}$ & 0,678 & 0,662 & 0,580 & $\% 90,80$ \\
$\mathrm{HC}$ & 0,589 & $\mathbf{0 , 0 0 0}$ & 0,347 & 0,149 & 0,824 & $\% 91,26$ \\
$\mathrm{CO}_{2}$ & $\mathbf{0 , 0 0 0}$ & 0,184 & 0,978 & 0,255 & 0,406 & $\% 98,99$ \\
$\mathrm{NO}$ & $\mathbf{0 , 0 0 0}$ & $\mathbf{0 , 0 0 0}$ & 0,970 & 0,031 & $\mathbf{0 , 0 0 2}$ & \\
\hline
\end{tabular}

Anlamlı - $(0,000<\mathrm{p} \leq 0,05)$

(A: Metanol oranı, B: Yük, AB: Metanol oranı * Yük, A $^{2}$ : Metanol oranı* Metanol oranı, B 2 : Yük * Yük)

\section{BULGULAR VE TARTIŞMA (RESULTS AND DISCUSSIONS)}

Metanol oranına ve motor yüküne bağlı olarak FEV ve FÖYT değerlerindeki değişimler sırasıyla Şekil 2 ve Şekil 3'te gösterilmektedir. Grafikler incelendiğinde artan motor yükünün FEV değerini artırırken, FÖYT değerini ise düşürdüğü görülmektedir. Diğer taraftan, artan metanol oranının ise FEV değerini hafif düşürürken, FÖYT değerini artırdığı açıkça anlaşılmaktadır. En yüksek FEV değeri \%100 benzin içerikli yakıt ile $14 \mathrm{~kg}$ motor yükünde \%34,70 olarak bulunmuştur. Aynı motor yükü değerinde $\% 10$ metanol içerikli yakıt kullanımı ile elde edilen FEV değeri \%34,00 iken, \%20 metanol içerikli yakıt ile \%31,50 olarak elde edilmiştir. Buna göre, benzine $\% 10$ metanol ve $\% 20$ metanol ilave edilmesi ile FEV değerleri \%100 benzine kıyasla sırasıly \%2,06 ve \%10,16 oranlarında azalmıştır.
Metanol-benzin karışımlarının düşük alt 1sıl değerinden dolayı motor 1sıl veriminin düşmesi ve özellikle sıkıştırma işlemlerinde kaybedilen işin artmasına bağlı olarak faydalı işin azalması gibi etkenlerin bu duruma yol açtığı söylenebilir. Metanolün düşük alt 1sıl değeri nedeniyle FEV'i düşürdüğü bulgusu literatürdeki aşağıdaki referanslar ile uyumludur $[23,24]$.

Diğer taraftan en yüksek FÖYT değeri $6 \mathrm{~kg}$ motor yükünde $\% 20$ metanol içerikli yakıt ile $0,38 \mathrm{~kg} / \mathrm{kWh}$ olarak elde edilmiştir. Artan metanol oranı ile FÖYT değerinin artması metanolün alt 1sıl değerinin benzine göre düşük olmasından kaynaklanmaktadır. Tablo 1'de de gösterildiği gibi benzinin alt 1sıl değeri 44,0 $\mathrm{MJ} / \mathrm{kg}$ iken, metanolün alt 1sıl değeri 20,05 MJ/kg'dır. Benzine metanol ilavesi ile yakıt karışımlarının alt ısıl değerleri düşmekte ve motordan aynı çıkış gücünün alınabilmesi için daha fazla yakıta ihtiyaç 
$\begin{array}{lcll}\text { duyulmaktadır. } & \text { Böylece, FÖYT } & \text { değeri artış } & \text { tarafından da benzer sonuçlar gözlemlenmiştir }[12, \\ \text { göstermektedir. } & \text { Literatürdeki } & \text { araştırmacılar } & 36] .\end{array}$

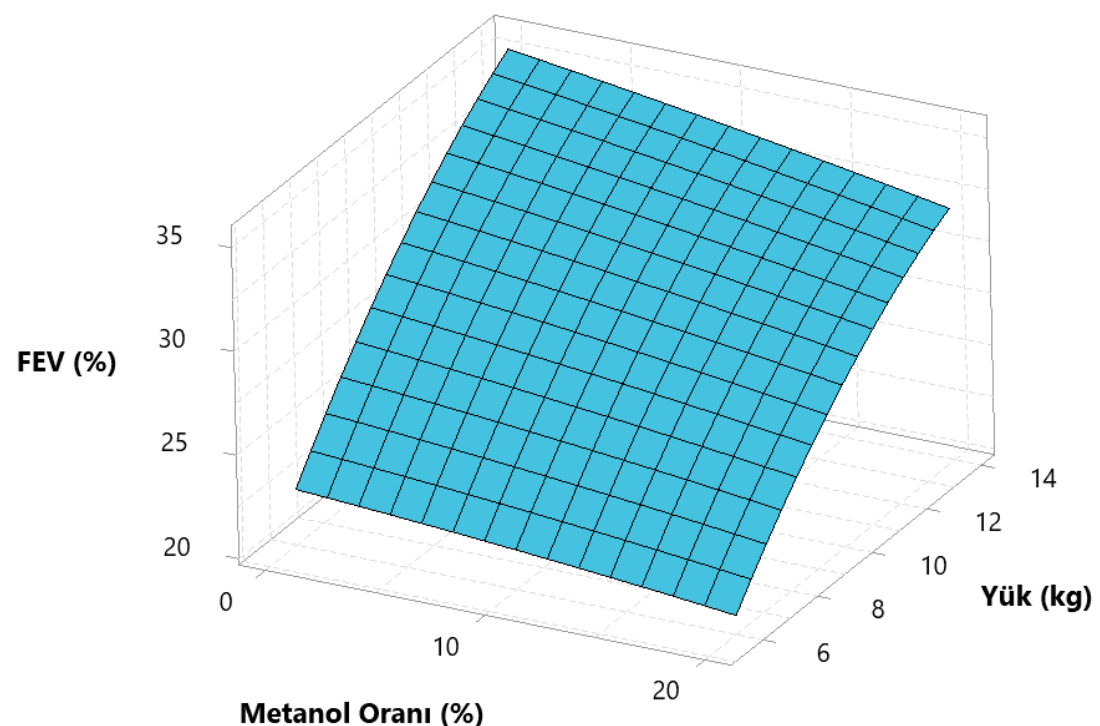

Şekil 2. Metanol oranı ve motor yüküne bağlı olarak FEV değişimi (The variation of BTE depending on the methanol ratio and engine load)

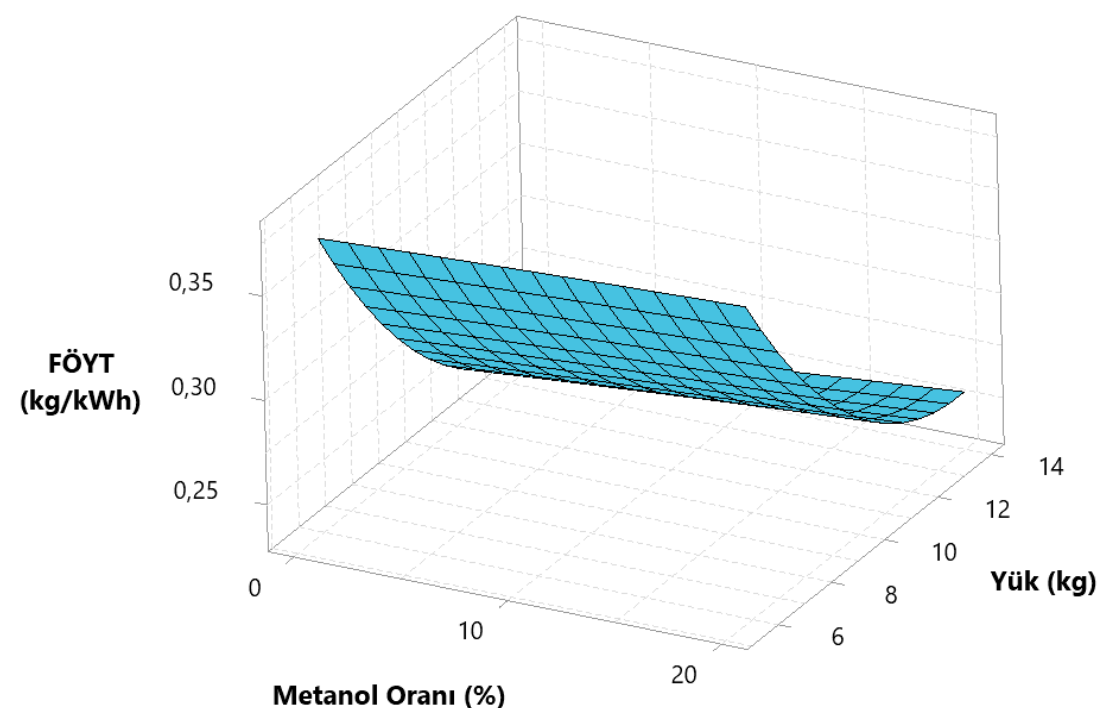

Şekil 3. Metanol oranı ve motor yüküne bağlı olarak FÖYT değişimi (The variation of BSFC depending on the methanol ratio and engine load)

Şekil 4'te metanol oranına ve motor yüküne bağlı olarak NO emisyonu değişimleri gösterilmektedir. NO emisyonu doğrudan silindir içi sıcaklıkla ve yanma odasındaki oksijen fazlalığı ile ilgili bir emisyon türüdür. Silindir içi sıcaklığın özellikle 1500$1600{ }^{\circ} \mathrm{C}$ değerlerine çıkmasıyla NO emisyonları aşırı artış göstermektedir. Buna ilaveten, silindir içi sıcaklığı artırıcı yönde etki yapan tüm faktörler NO emisyonunun da artmasına sebep olacaktır. Grafik incelendiğinde, en düşük NO emisyonunun $\% 10$ metanol ilaveli yakıt ile ortaya çıktığı görülmektedir. Metanol benzine göre daha yüksek buharlaşma gizli ısısına sahip olduğundan, emme zamanının sonunda yanıcı karışım sıcaklıkları ve maksimum yanma sıcaklığı değerleri benzine göre nispeten daha düşüktür [36]. Bu sayede NO emisyonları daha düşük çıkmaktadır. Metanol kullanımı ile NO emisyonlarının azaldığına dair benzer sonuçlara sahip çalışmalar bulunmaktadır [37,38]. En düşük NO emisyonu 474 ppm olarak \%10 metanol ilavesi ile bulunurken, metanol oranının \%20'ye çıkartılmasıyla NO emisyonları tekrar hafif artış göstermiştir. Metanolün oksijen içerikli bir yakıt olması nedeniyle artan metanol oranına bağlı olarak yanma odasında oksijen fazlalığı olmakta ve bu durum NO emisyonlarının tekrar artma eğilimine geçmesine 
sebep olmaktadır [39]. Metanol oranının tersine, artan motor yükü ile NO emisyonunun oldukça arttığı gözlemlenmektedir. En düşük NO emisyonunun görüldüğü $\% 10$ metanol oranında yapılan kıyaslamaya göre motor yükünün 6 kg'dan 14 kg'a çıkmasıyla NO emisyonu yaklaşık 2,5 kat artmıştır. Motor yükü silindir içi sıcaklığı artıran bir parametre olduğu için NO emisyonu artış1 gerçekleşmiştir.

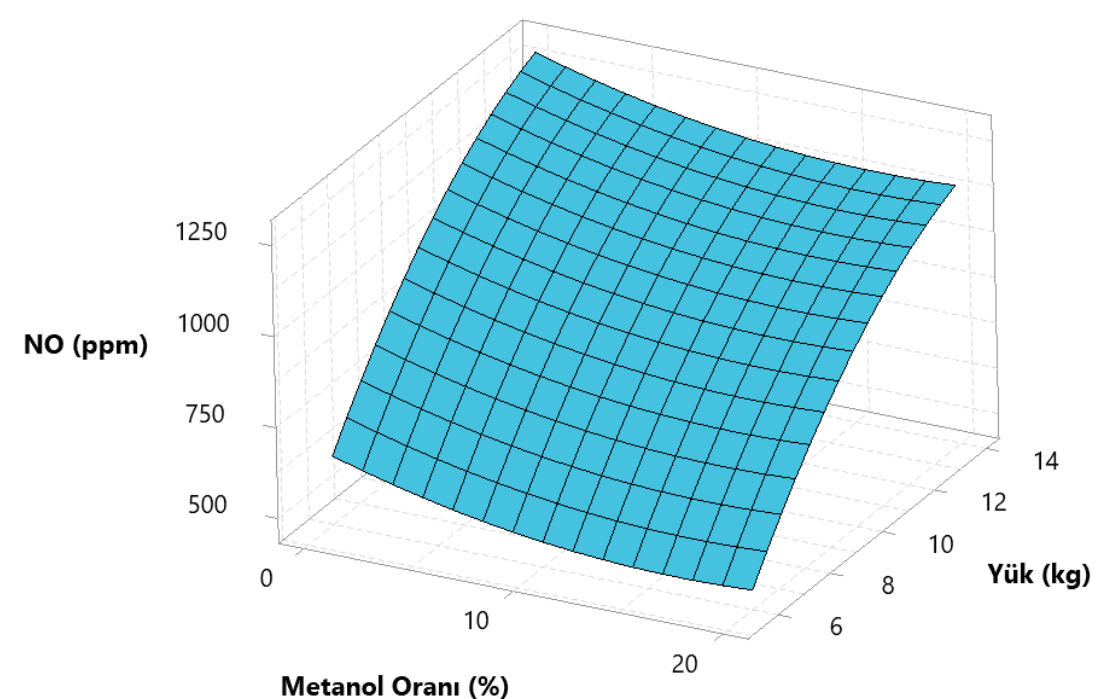

Şekil 4. Metanol oranı ve motor yüküne bağlı olarak NO emisyonu değişimi (The variation of NO emission depending on the methanol ratio and engine load)

Eksik yanma ürünü olan $\mathrm{CO}$ ve $\mathrm{HC}$ emisyonları ile tam yanma ürünü olan $\mathrm{CO}_{2}$ emisyonlarının metanol oranına ve motor yüküne bağlı olarak değişimi sırasıyla Şekil 5, Şekil 6 ve Şekil 7'de gösterilmektedir. Hem $\mathrm{CO}$ hem de $\mathrm{HC}$ emisyonu herhangi bir sebeple ortaya çıkan eksik yanmadan kaynaklı emisyonlardır [40,41]. HC ve CO grafikleri incelendiğinde, en düşük CO emisyonu \%20 metanol ile elde edilirken, en düşük $\mathrm{HC}$ emisyonu $\% 10$ metanol ile bulunmuştur. Metanol oranının \%20’ye çıkarılması HC emisyonunun tekrar artmasına sebep olurken, CO emisyonları azalmaya devam etmiştir. Metanolün daha yüksek buharlaşma gizli 1sısı silindir içi sıcaklığı düşürür ve bu bazen yanma odası duvarlarının yakınında yanmanın gerçekleşmemesine veya kısmi yanmaya neden olabilir. Bu yüzden \%20 metanol oranı ile karışımın buharlaşma gizli 1sısı çok düştüğü için HC emisyonlarının tekrar artışa geçtiği düşünülmektedir. Diğer taraftan, artan metanol oranı ile silindir içinde oksijen varlığının artması, oksijen yetersizliği nedeniyle ortaya çıkan $\mathrm{CO}$ emisyonlarını azaltmıştır. Literatürde benzer sonuçlar elde edilen çalışmalar mevcuttur $[42,43]$. Motor yükü değişimi açısından $\mathrm{HC}$ ve $\mathrm{CO}$ grafikleri incelendiğinde, daha yüksek motor yüklerinde, nispeten daha zengin karışımların yanması nedeniyle yanma odası içindeki sicaklık artmakta ve yüksek sicaklıklarda yanma, tam yanma oranını artırdığı için $\mathrm{HC}$ ve CO emisyonlarını azaltmaktadir. 


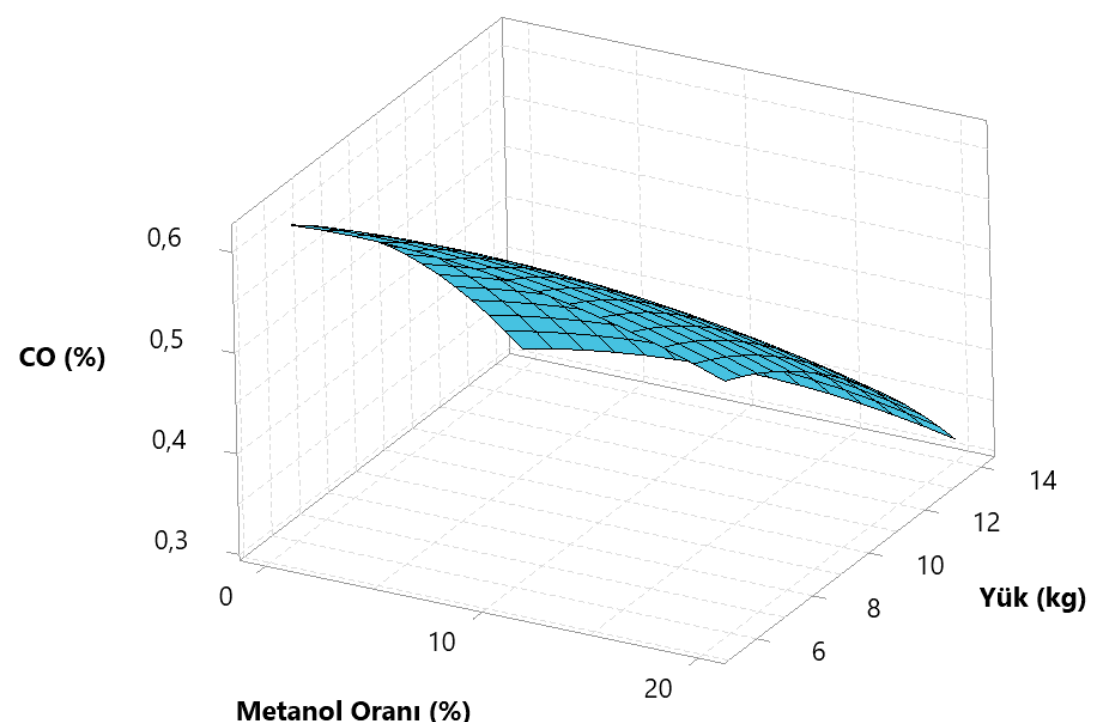

Şekil 5. Metanol oranı ve motor yüküne bağlı olarak CO emisyonu değişimi (The variation of CO emission depending on the methanol ratio and engine load)

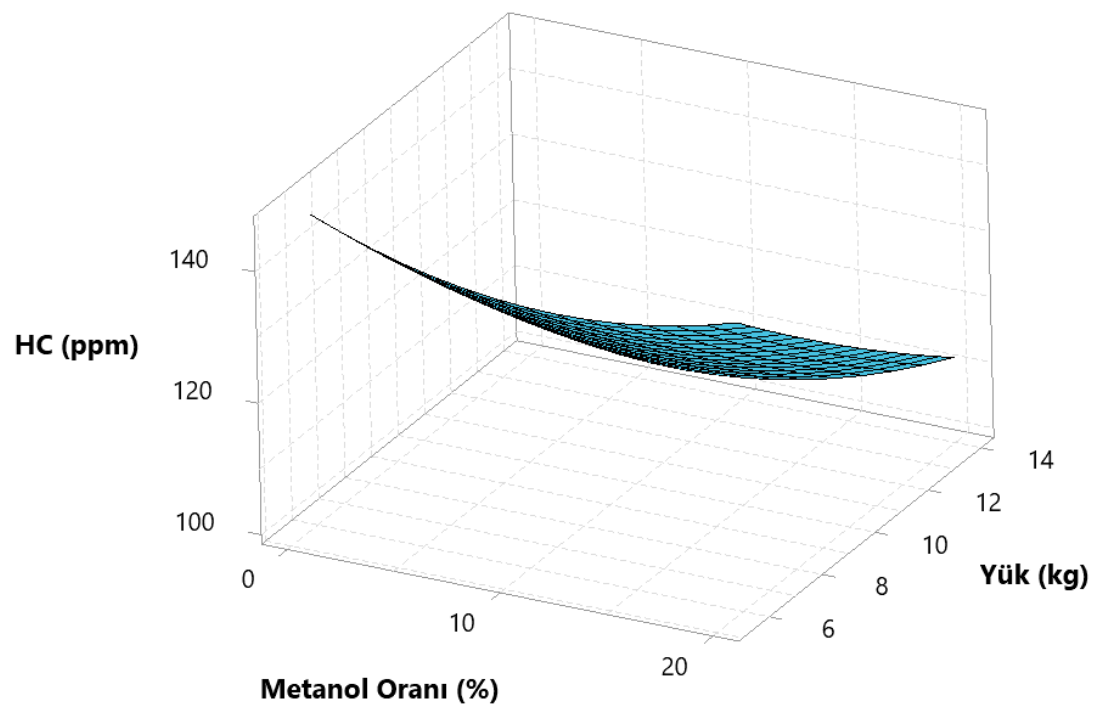

Şekil 6. Metanol oranı ve motor yüküne bağlı olarak HC emisyonu değişimi (The variation of HC emission depending on the methanol ratio and engine load)

$\mathrm{CO}$ ve $\mathrm{HC}$ emisyonlarının tersine, $\mathrm{CO}_{2}$ emisyonu tam yanma reaksiyonunda ortaya çıkan bir emisyondur. Yanma reaksiyonunda karbon atomları yeterli oksijeni bulabilirse $\mathrm{CO}_{2}$ emisyonuna dönüşür. Oksijen yetersizliği durumunda $\mathrm{CO}$ emisyonu olarak kalır. Dolayısıyla, $\mathrm{CO}$ emisyonu azalırken $\mathrm{CO}_{2}$ emisyonunun artması beklenen bir durumdur. Metanolün içeriğindeki oksijen sayesinde tam yanma oranını artırarak $\mathrm{CO}$ emisyonlarını azalttığından yukarıda bahsedilmişti. Buna göre $\mathrm{CO}_{2}$ emisyonunun artması beklenir ve Şekil 7 incelendiğinde artan metanol oranına bağlı olarak $\mathrm{CO}_{2}$ emisyonunun arttığ açık bir şekilde anlaşılmaktadır. Buna ilaveten, artan motor yükü de $\mathrm{CO}_{2}$ emisyonunu artırmıştır. Metanol içeriğine bağlı olarak $\mathrm{CO}_{2}$ emisyonunun arttığı bazı çalışmalarda rapor edilmiştir [44, 45]. 


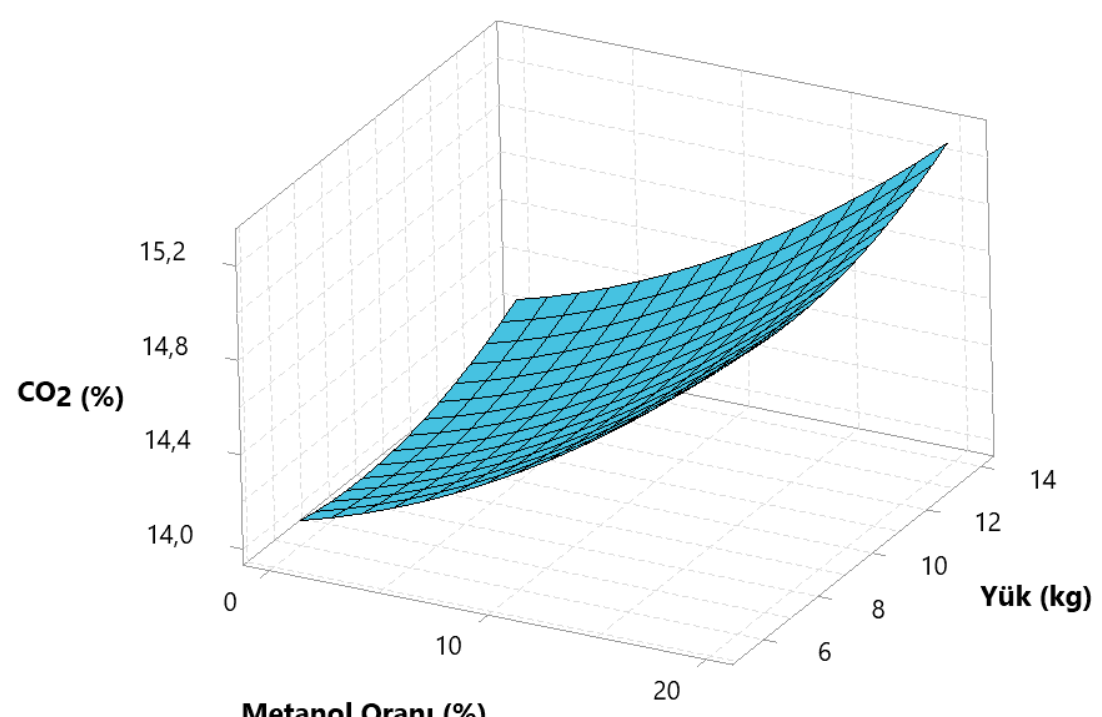

Şekil 7. Metanol oranı ve motor yüküne bağlı olarak $\mathrm{CO}_{2}$ emisyonu değişimi (The variation of $\mathrm{CO}_{2}$ emission depending on the methanol ratio and engine load)

3.1. Optimizasyon ve Doğrulama (Optimization and Validation)

$\mathrm{Bu}$ çalışmadaki optimizasyonun amacı, optimum metanol oranı ile motor yükünü belirlemek ve optimum çalışma şartlarına karşılık gelen en yüksek performans ve en düşük emisyon seviyelerini elde etmektir. Yukarıdaki bölümde gösterilen 3 boyutlu grafiklerde her bir cevap için ayrı ayrı optimum metanol oranı ve motor yükü gösterilmişti ancak bu bölümde tüm cevapların optimizasyonu eşzamanlı olarak gerçekleştirilmiştir. Optimizasyondan elde edilen sonuçlar Şekil 8'de gösterilmiştir. Optimizasyon sonuçlarına göre optimum metanol oran $1 \% 7$ çıkarken, optimum motor yükü $12 \mathrm{~kg}$ olarak bulunmuştur. Optimum metanol oranı ve motor yüküne karşılık gelen cevaplar ise FEV, FÖYT, CO,
$\mathrm{HC}, \mathrm{CO}_{2}$ ve $\mathrm{NO}$ için sirasıyla \%32,037, 0,251 $\mathrm{kg} / \mathrm{kWh}, \% 0,384,110,05 \mathrm{ppm}, \% 14,35$ ve 1090,358 ppm olarak ortaya çıkmıştır. Ayrıca, optimizasyon ile elde edilen sonuçların doğruluğu ile ilgili soru işaretlerinin ortadan kaldırılması için bir doğrulama çalışması yapılması gerekmektedir. $\mathrm{Bu}$ doğrulama çalışmasında, optimizasyondan elde edilen optimum çalışma parametreleri ile deneysel sonuçlar karşılaştırılmıştır. Optimum sonuçlar ile deney sonuçlarının kıyaslaması Tablo 7'de verilmiştir. Bu doğrulama çalışmasında ortaya çıkan hata oranlarının \%6'nın altında olması nedeniyle optimizasyon çalışmasının başarılı olduğu söylenebilir. Literatürdeki optimizasyon çalışmalarında benzer seviyede veya daha yüksek oranda hata ile optimizasyon yapılan çalışmalar mevcuttur $[18,46]$. 


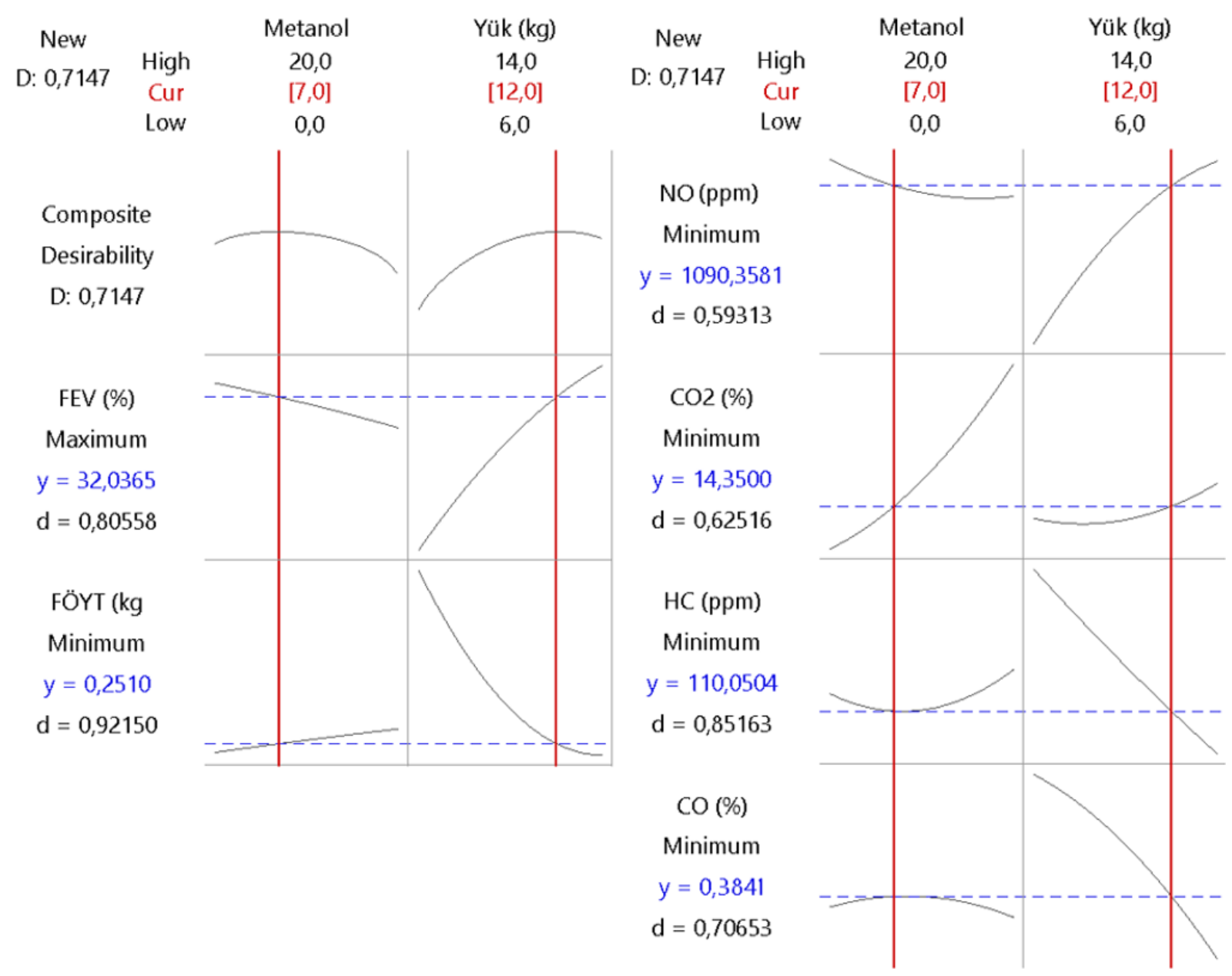

Şekil 8. Optimum çalışma şartları ve karşılık gelen cevaplar (Optimum operating conditions and corresponding answers)

Tablo 7. Doğrulama uygulamas1 (Application of validation)

\begin{tabular}{|c|c|c|c|c|c|c|c|c|}
\hline Metanol oranı (\%) & Yük (kg) & & FEV $(\%)$ & FÖYT (kg/kWh) & $\mathrm{CO}(\%)$ & $\mathrm{CO}_{2}(\%)$ & $\mathrm{HC}(\mathrm{ppm})$ & NO (ppm) \\
\hline \multirow[t]{3}{*}{7} & 12 & Optimum & 32,037 & 0,251 & 0,384 & 14,35 & 110,05 & 1090,358 \\
\hline & & Deneysel & 32,835 & 0,254 & 0,366 & 13,952 & 104,47 & 1093,733 \\
\hline & & Hata $(\%)$ & 2,43 & 0,99 & 4,86 & 2,85 & 5,34 & 0,31 \\
\hline
\end{tabular}

\section{SONUÇLAR (CONCLUSIONS)}

$\mathrm{Bu}$ çalışmada, optimum metanol oranı ve motor yükünü belirleyerek en yüksek performans ve en düşük emisyonları elde etmek amacıyla RSM ile optimizasyon çalışması yapılmıştır. RSM optimizasyonu için gerekli veriler, üç farklı metanol oranında $(\% 0, \% 10$ ve $\% 20)$, ve beş farklı motor yükünde $(6,8,10,12$ ve $14 \mathrm{~kg})$ yapılan deneylerden alınmıştır. Elde edilen sonuçlar aşağıda listelenmiştir:

- $\quad$ Optimum metanol oranı \%7 ve motor yükü 12 kg olarak tespit edilmiştir.

- Elde edilen regresyon sonuçları tüm yanıtlar için \%90'dan büyük $\mathrm{R}^{2}$ değerlerinin elde edildiği ve buna istinaden, oluşturulan RSM modelinin, farklı motor yükünde buji ateşlemeli motor cevapları üzerindeki metanol oranının etkisini doğru bir şekilde verme yeteneğine sahip olduğunu göstermektedir.

- Optimum metanol oranı ve motor yüküne karşılık gelen cevaplar FEV için \%32,037, FÖYT için 0,251 kg/kWh, CO için \%0,384, $\mathrm{HC}$ için 110,05 ppm, $\mathrm{CO}_{2}$ için $\% 14,35$ ve NO için 1090,358 ppm olarak bulunmuştur.

- Metanol ilavesinin genel olarak emisyonları iyileştirdiği ancak diğer taraftan performansı az da olsa kötüleştirdiği sonucuna varılmıştır.

- Optimizasyon ve doğrulama çalışmaları ile elde edilen sonuçlar, metanol yakıt 
karışımlarının kullanıldığı buji ateşlemeli bir motorun RSM ile \%6'nın altında bir hata oranıyla başarılı bir şekilde optimize edilebileceğini göstermektedir.

\section{ACKNOWLEDGMENT (TEŞEKKÜR)}

$\mathrm{Bu}$ çalışma Kırıkkale Üniversitesi Bilimsel Araştirma Projeleri Koordinasyon Birimi tarafından desteklenmiştir (Proje No: 2018/067). BAP birimine desteklerinden dolayı teşekkür ederiz.

\section{ÇIKAR ÇATIŞMASI BİLDİRIMİ (CONFLICT OF INTEREST STATEMENT)}

Yazarlar tarafından herhangi bir çıkar çatışması bildirilmemiştir.

\begin{tabular}{ll}
\hline KISALTMALAR & \\
\hline ANOVA & varyans analizi \\
$\mathrm{CO}$ & karbon monoksit \\
$\mathrm{CO}_{2}$ & karbon dioksit \\
FEV & fren efektif verimi \\
FÖYT & fren özgül yakıt tüketimi \\
$\mathrm{HC}$ & hidrokarbon \\
NO & azot monoksit \\
RSM & cevap yüzey metodu \\
\hline
\end{tabular}

\section{REFERENCES (KAYNAKLAR)}

[1] S. Baidya, S., J. Borken-Kleefeld, "Atmospheric emissions from road transportation in India", Energy Policy, vol. 37, no. 10, pp. 3812-3822, 2009.

[2] T. M. I. Mahlia, Z. A. H. S. Syazmi, M. Mofijur, A. P. Abas, M. R. Bilad, H. C. Ong, A. S. Silitonga, "Patent landscape review on biodiesel production: Technology updates", Renewable and Sustainable Energy Reviews, vol. 118, pp. 109526, 2020.

[3] D. Sperling, Two billion cars: Driving toward sustainability. New York: Oxford University Press, pp. 93-94, 2009.

[4] B. Dogan, A. Cakmak, M. K. Yesilyurt, D. Erol, "Investigation on 1-heptanol as an oxygenated additive with diesel fuel for compression-ignition engine applications: An approach in terms of energy, exergy, exergoeconomic, enviroeconomic, and sustainability analyses", Fuel, vol. 275, pp. 117973 , 2020.

[5] A. Elfasakhany, "Comparisons of using ternary and dual gasoline-alcohol blends in performance and releases of SI engines", Arabian Journal for Science and Engineering, pp. 1-14, 2021.

[6] B., Dogan, D. Erol, H. Yaman, E. Kodanli, "The effect of ethanol-gasoline blends on performance and exhaust emissions of a spark ignition engine through exergy analysis", Applied Thermal Engineering, vol. 120, pp. 433-443, 2017.

[7] M. B. Çelik, B. Özdalyan, F. Alkan, "The use of pure methanol as fuel at high compression ratio in a single cylinder gasoline engine", Fuel, vol. 90, no. 4, pp. 1591-1598, 2011.

[8] H. Liu, Z. Wang, Y. Long, S. Xiang, J. Wang, S. W. Wagnon, "Methanol-gasoline dual-fuel spark ignition (DFSI) combustion with dual-injection for engine particle number $(\mathrm{PN})$ reduction and fuel economy improvement", Energy, vol. 89, pp. 1010$1017,2015$.

[9] I. Gravalos, D. Moshou, T. Gialamas, P. Xyradakis, D. Kateris, Z. Tsiropoulos, "Emissions characteristics of spark ignition engine operating on lower e higher molecular mass alcohol blended gasoline fuels", Renewable Energy, vol. 50, pp. 2732, 2013.

[10] J. Vancoillie, J. Demuynck, L. Sileghem, M. V. D. Ginste, S. Verhelst, L. Brabant, L. V. Hoorebeke, "The potential of methanol as a fuel for flex-fuel and dedicated spark-ignition engines", Applied Energy, vol. 102, pp. 140-149, 2013.

[11] C. Gong, Z. Li, K. Huang, F. Liu, "Research on the performance of a hydrogen/methanol dualinjection assisted spark-ignition engine using lateinjection strategy for methanol", Fuel, vol. 260, pp. 116403, 2020.

[12] M. K. Balki, C. Sayin, "The effect of compression ratio on the performance, emissions and combustion of an SI (spark ignition) engine fueled with pure ethanol, methanol and unleaded gasoline", Energy, vol. 71, pp. 194-201, 2014.

[13] S. A. Shirazi, B. Abdollahipoor, J. Martinson, B. Windom, T. D. Foust, K. F. Reardon, "Effects of dual-alcohol gasoline blends on physiochemical properties and volatility behavior", Fuel, vol. 252, pp. 542-552, 2019.

[14] B. Waluyo, M. Setiyo, I. N. G Wardana, "Fuel performance for stable homogeneous gasolinemethanol-ethanol blends", Fuel, vol. 294, pp. 120565 , 2021. 
[15] F. Xie, X. Li, X. Wang, Y. Su, W. Hong, "Research on using EGR and ignition timing to control load of a spark-ignition engine fueled with methanol", Applied Thermal Engineering, vol. 50, no. 1, pp. 1084-1091, 2013.

[16] B. S. N. Prasad, J. K. Pandey, G. N. Kumar, "Impact of changing compression ratio on engine characteristics of an SI engine fueled with equivolume blend of methanol and gasoline", Energy, vol. 191, pp. 116605, 2020.

[17] Y. Çay, I. Korkmaz, A. Çiçek, F. Kara "Prediction of engine performance and exhaust emissions for gasoline and methanol using artificial neural network", Energy, vol. 50, no. 1, pp. 177-186, 2013.

[18] A. N. Kumar, P. S. Kishore, K. B. Raju, B. Ashok, R. Vignesh, A. K. Jeevanantham, K. Nanthagopal, A. Tamilvanan, "Decanol proportional effect prediction model as additive in palm biodiesel using ANN and RSM technique for diesel engine", Energy, vol. 213, pp. 119072, 2020.

[19] O. I. Awad, R. Mamat, O. M. Ali, W. H. Azmi, K. Kadirgama, I. M. Yusri, A. M. Leman, T. Yusaf, "Response surface methodology (RSM) based multi-objective optimization of fusel oil -gasoline blends at different water content in SI engine", Energy Conversion and Management, vol. 150, pp. 222-241, 2017.

[20] T. Kumar, R. Mohsin, Z. A. Majid, M. F. A. Ghafir, A. M. Wash, "Experimental study of the antiknock efficiency of high-octane fuels in spark ignited aircraft engine using response surface methodology", Applied Energy, vol. 259, pp. 114150, 2020.

[21] G. Najafi, B. Ghobadian, T. Yusaf, S. Mohammad, S. Ardebili, R. Mamat, "Optimization of performance and exhaust emission parameters of a SI (spark ignition) engine with gasoline-ethanol blended fuels using response surface methodology", Energy, vol. 90, no. 2, pp. 1815-1829, 2015.

[22] A. S. Onawumi, O. S. I. Fayomi, S. T. A. Okolie, T. A. Adio, N. E. Udoye, A. U. Samuel, "Determination of a spark 1gnition engine's performance parameters using response surface methodology", Energy Procedia, vol. 157, pp. 14121422, 2019.

[23] S. Sarıkoç, "Effect of H2 addition to methanol-gasoline blend on an SI engine at various lambda values and engine loads: A case of performance, combustion, and emission characteristics", Fuel, vol. 297, pp. 120732, 2021.
[24] Y. Li, J. Gong, Y. Deng, W. Yuan, J. Fu, B. Zhang, "Experimental comparative study on combustion, performance and emissions characteristics of methanol, ethanol and butanol in a spark ignition engine", Applied Thermal Engineering, vol. 115, pp. 53-63, 2017.

[25] S. Özer, "Alkollerin içten yanmalı motorlarda alternatif yakıt olarak kullanılması", Uludă̆ Üniversitesi Mühendislik-Mimarlık Fakültesi Dergisi, vol. 19, no. 1, pp. 100-101, 2014.

[26] V. K. Sharma, V. Kumar, R. S. Joshi, "Parametric study of aluminium-rare earth based composites with improved hydrophobicity using response surface method", Journal Of Materials Research And Technology, vol. 9, no. 3, pp. 49194932, 2020.

[27] M. Alrugaibah, Y. Yagiz, L. Gu, "Use natural deep eutectic solvents as efficient green reagents to extract procyanidins and anthocyanins from cranberry pomace and predictive modeling by RSM and artificial neural networking", Separation and Purification Technology, vol. 255, pp. 117720, 2021.

[28] A. Sharma, Y. Singh, N. K. Singh, A. Singla, H. C. Ong, W. H. Chen, "Effective utilization of tobacco (Nicotiana tabaccum) for biodiesel production and its application on diesel engine using response surface methodology approach", Fuel, vol. 273, pp. 117793, 2020.

[29] S. Uslu, M. B. Celik, "Performance and exhaust emission prediction of a SI engine fueled with 1-amyl alcohol-gasoline blends: An ANN coupled RSM based optimization", Fuel, vol. 265, pp. 116922 , 2020.

[30] S. Simsek, S. Uslu, "Determination of a diesel engine operating parameters powered with canola, safflower and waste vegetable oil based biodiesel combination using response surface methodology (RSM)", Fuel, vol. 270, pp. 117496, 2020 .

[31] M. Ghanbari, L. Mozafari-Vanani, M. Dehghani-Soufi, A. Jahanbakhshi, "Effect of alumina nanoparticles as additive with diesel-biodiesel blends on performance and emission characteristic of a sixcylinder diesel engine using response surface methodology (RSM)", Energy Conversion and Management: X, vol. 11, pp. 100091, 2021.

[32] S. Dey, N.M. Reang, P.K. Das, M. Deb, "Comparative study using RSM and ANN modelling 
for performance-emission prediction of $\mathrm{CI}$ engine fuelled with bio-diesohol blends: A fuzzy optimization approach", Fuel, vol. 292, pp. 120356 , 2021.

[33] H. Yaman, M. K. Yesilyurt, S. Uslu, "Simultaneous optimization of multiple engine parameters of a 1-heptanol / gasoline fuel blends operated a port-fuel injection spark-ignition engine using response surface methodology approach", Energy, vol. 238, no. (Part C), pp. 122019, 2021.

[34] S. Simsek, S. Uslu, "Investigation of the effects of biodiesel/2-ethylhexyl nitrate (EHN) fuel blends on diesel engine performance and emissions by response surface methodology (RSM)", Fuel, vol. 275, pp. 118005, 2020.

[35] M. Dana, M. A. Sobati, S. Shahhosseini, A. Ansari, "Optimization of a continuous ultrasound assisted oxidative desulfurization (UAOD) process of diesel using response surface methodology (RSM) considering operating cost", Chinese Journal of Chemical Engineering, vol. 28, no. 5, pp. 1384-1396, 2020 .

[36] A. K. Agarwal, H. Karare, A. Dhar, "Combustion, performance, emissions and particulate characterization of a methanol-gasoline blend (gasohol) fuelled medium duty spark ignition transportation engine", Fuel Processing Technology, vol. 121, pp. 16-24, 2014.

[37] B. Wu, L. Wang, X. Shen, R. Yan, P. Dong, "Comparison of lean burn characteristics of an SI engine fueled with methanol and gasoline under idle condition", Applied Thermal Engineering, vol. 95, pp. 264-270, 2016.

[38] M. Canakci, A. N. Ozsezen, E. Alptekin, M. Eyidogan, "Impact of alcohol-gasoline fuel blends on the exhaust emission of an SI engine", Renewable Energy, vol. 52, pp. 111-117, 2013.

[39] S. Raviteja, G. N. Kumar, "Effect of hydrogen addition on the performance and emission parameters of an SI engine fueled with butanol blends at stoichiometric conditions", International Journal of Hydrogen Energy, vol. 40, no. 30, pp. 9563-9569, 2015.

[40] S. Simsek, S. Uslu, H. Simsek, G. Uslu, "Multi-objective-optimization of process parameters of diesel engine fueled with biodiesel/2-ethylhexyl nitrate by using Taguchi method", Energy, vol. 231, pp. 120866, 2021.
[41] S. Simsek, S. Uslu, R. Coştu, "A novel approach to study the effect of motor silk-added pyrolysis tire oil on performance and emission characteristics of a diesel engine", Fuel, vol. 288, pp. 119668, 2021.

[42] A. Elfasakhany, "Exhaust emissions and performance of ternary iso-butanol-bio-methanolgasoline and n-butanol-bio-ethanol-gasoline fuel blends in spark-ignition engines: Assessment and comparison", Energy, vol. 158, pp. 830-844, 2018.

[43] T. C. C. De Melo, G. B. Machado, C. R. Belchior, M. J. Colaço, J. E. Barros, E. J. de Oliveira, D. G. de Oliveira, "Hydrous ethanol-gasoline blendsCombustion and emission investigations on a FlexFuel engine". Fuel, vol. 97, pp. 796- 804, 2012.

[44] İ. Örs, B. S. Kul, M. Ciniviz, "A Comparative Study of Ethanol and Methanol Addition Effects on Engine Performance, Combustion and Emissions in the SI Engine", International Journal of Automotive Science and Technology, vol. 4, no. 2, pp. 59-69, 2020.

[45] Z. Chen, L. Wang, X. Yuan, Q. Duan, B. Yang, K. Zeng, "Experimental investigation on performance and combustion characteristics of sparkignition dual-fuel engine fueled with methanol/natural gas.", Applied Thermal Engineering, vol. 150, pp. 164-174, 2019.

[46] A. N. Abdalla, H. Tao, S. A. Bagaber, O. M. Ali, M. Kamil, X. Ma, O. I. Awad, "Prediction of emissions and performance of a gasoline engine running with fusel oil-gasoline blends using response surface methodology", Fuel, vol. 253, pp. 1-14, 2019.

This is an open access article under the CC-BY license (https://creativecommons.org/licenses/by/4.0/)

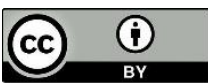

